\title{
Arterial revascularization in primary coronary artery bypass grafting: Direct comparison of 4 strategies-Results of the Stand-in-Y Mammary Study
}

Giuseppe Nasso, MD, ${ }^{\text {a }}$ Roberto Coppola, MD ${ }^{\mathrm{b}}$ Raffaele Bonifazi, MD, ${ }^{\mathrm{a}}$ Felice Piancone, MD, ${ }^{\mathrm{a}}$ Giuseppe Bozzetti, MD, ${ }^{\mathrm{a}}$ and Giuseppe Speziale, $\mathrm{MD}^{\mathrm{a}}$

Objective: It is unclear (1) whether the use of 2 arterial conduits rather than a single conduit in multivessel coronary artery bypass grafting significantly improves results despite the concomitant use of saphenous vein grafts and (2) whether any among different configurations of composite grafts (left/right thoracic arteries and radial artery) offers an advantage over the others.

Methods: Eight hundred fifteen patients were randomized to one of 3 different strategies of revascularization by using the left thoracic artery plus the right thoracic artery or using the left thoracic artery plus the radial artery. Venous grafts were used for the remaining targets. Patients randomized to receive 1 arterial graft served as control subjects. Operative mortality and morbidity were comparable among groups.

Results: The rate of cerebrovascular complications was not statistically lower among patients receiving 2 arterial grafts. At 2 years, overall survival was not significantly different among groups $(P=.59)$. Cardiac event-free survival was significantly better in patients receiving 2 arterial grafts versus control subjects $(P<.0001)$, even among elderly patients $(P=.022)$. The 3 investigated strategies using 2 arterial conduits were similar concerning early and midterm results.

Conclusions: Revascularization with 2 arterial conduits offers better midterm event-free survival than a single arterial graft, irrespective of which second-choice arterial conduit is used (radial artery or right thoracic artery), the simultaneous use of saphenous vein grafts, and the patient's age.

The proved superiority of internal thoracic arteries (ITAs) over great saphenous vein (GSV) grafts in terms of longterm outcome, which is particularly evident when the left anterior descending coronary artery (LAD) is involved, ${ }^{1-3}$ has pushed surgeons to explore the potentials of total arterial revascularization.

Even the use of 1 additional arterial graft has been indicated to improve the results of coronary artery bypass grafting (CABG). Bilateral ITA grafting in conjunction with GSV grafts has ameliorated the survival and reduced the risk of reoperation compared with single ITA grafting plus GSV grafting to the remaining coronary targets. ${ }^{4-6}$ Such benefits might be evident, even with the use of composite grafts ${ }^{7}$ and in elderly patients at midterm follow-up. ${ }^{8}$ Nonetheless, recent data suggest that the gap between the results of free arterial grafts and GSV grafts might be reducing in the contemporary era. ${ }^{9}$

Composite grafts are among the technical improvements proposed to allow arterial revascularization with reduced

\footnotetext{
From the Division of Cardiac Surgery, ${ }^{\mathrm{a}}$ Anthea Hospital, Bari, Italy; and the Division of Cardiac Surgery, ${ }^{\mathrm{b}}$ Villa Azzurra Hospital, Rapallo, Italy.

Received for publication July 3, 2008; revisions received Sept 22, 2008; accepted for publication Oct 16, 2008.

Address for reprints: Giuseppe Nasso, MD, Division of Cardiac Surgery, Anthea Hospital, Via C. Rosalba, 35-37, 70124 Bari, Italy (E-mail: gnasso@libero.it).

J Thorac Cardiovasc Surg 2009;137:1093-100

$0022-5223 / \$ 36.00$

Copyright (c) 2009 by The American Association for Thoracic Surgery

doi:10.1016/j.jtcvs.2008.10.029
}

conduit use and preserved left internal thoracic artery (LITA)-LAD grafting. The Y-side configuration of a free right internal thoracic artery (RITA) anastomosed end-toside to a pedicled LITA is effective to obtain an adequate revascularization of the whole left coronary system, ${ }^{10}$ but there are no studies analyzing the results of such graft configuration versus other strategies of revascularization with more than 1 arterial conduit, either free or in the $\mathrm{Y}$ configuration. Controversies exist about whether the use of more than 1 arterial conduit significantly ameliorates the patient's outcome, even though GSV grafts are simultaneously used to complete the operation, in comparison with the established strategy of using LITA-LAD grafts plus GSV grafts. A specific subpopulation of patients (ie, the elderly, who are increasingly frequent in practice) are a major subject in these debates. The Stand-in-Y Mammary Study has been designed with the purpose to contribute to the knowledge base on these issues.

\section{MATERIALS AND METHODS \\ Aim}

We sought to compare in a prospective randomized investigation 3 different strategies of myocardial revascularization with the use of 2 arterial conduits in a contemporary (2003-2006) cardiac surgical experience.

\section{Inclusion of Patients}

The present study was prospectively started in January 2003. Each patient scheduled for coronary surgery was evaluated at the time of 


$$
\begin{aligned}
& \text { Abbreviations and Acronyms } \\
& \text { CABG }=\text { coronary artery bypass grafting } \\
& \text { CI }=\text { confidence interval } \\
& \text { CPB }=\text { cardiopulmonary bypass } \\
& \text { GSV }=\text { great saphenous vein } \\
& \text { ITA }=\text { internal thoracic artery } \\
& \text { LAD }=\text { left anterior descending coronary artery } \\
& \text { LITA }=\text { left internal thoracic artery } \\
& \text { OR }=\text { odds ratio } \\
& \text { RA }=\text { radial artery } \\
& \text { RITA }=\text { right internal thoracic artery }
\end{aligned}
$$

admission to the cardiac surgery unit. Patients were considered suitable to enter the Stand-in-Y Mammary Study on the basis of the following criteria:

- primary elective isolated myocardial revascularization for multivessel coronary disease with involvement of the LAD artery, according to the current guidelines, scheduled ${ }^{11}$;

- use of full cardiopulmonary bypass (CPB) planned; and

- availability of conduits (GSV; possibility to harvest the radial artery [RA] from the nondominant arm and to harvest the RITA).

By using historical data, a sample size calculation was performed, with a 0.8 statistical power, a $95 \% \mathrm{CI}$, and a $.05 \alpha$ level. The outcome end point for sample size calculation was the expected rate of graft failure in the arterial revascularization groups versus the traditional revascularization group. Taking into calculation a 0.33 rate of control to case patients, a 0.14 expected event rate among case patients and a 0.07 expected event rate among control subjects yielded a sample size of 636 cases. Sample size calculation was performed with PS Software version 2.1.30 for Windows.

Before randomization and according to institutional policy, all patients were subjected to echocardiographic Doppler evaluation of the ulnar compensation during RA compression in the nondominant arm, according to a previously described methodology. ${ }^{12}$ Evidence of adequate compensation was required for eligibility of RA harvest and to enter the study. Similarly, patients carrying more than 1 of the described risk factors for deep sternal wound infection (diabetes and obesity [body mass index $\geq 30])^{13}$ were not considered suitable for bilateral ITA harvest because of excessive risk of sternal wound infection; hence these individuals were excluded from the study before randomization. No modifications were included in the institutional protocols to comply with the study inclusion/exclusion criteria.

Additional exclusion criteria were as follows: redo procedure, planned use of any arterial graft other than thoracic arteries and the RA, any associated cardiac surgical procedure other than coronary surgery, and history of systemic inflammatory conditions, vasculitis, or thoracic/mediastinal radiation therapy. Decreased ejection fraction and advanced age were not among the exclusion criteria.

The local ethics committees provided formal approval to the protocol. Patients were asked to provide informed consent to enter the investigation. Enrolled patients were then randomized with the aid of a computerized algorithm to one of 4 groups corresponding to 4 different strategies of revascularization, as detailed below:

- Group 1. Y graft: in situ LITA graft to LAD artery and isolated RITA graft to secondary target with or without GSV graft(s) to revascularize the remaining target(s);

- Group 2. In situ RITA graft to the LAD plus in situ LITA graft with or without GSV graft(s) to revascularize the remaining target(s);

- Group 3. In situ LITA graft to the LAD plus free aortocoronary RA graft to the secondary target or Y graft: in situ LITA graft to the LAD and iso- lated RA segment to the secondary target with or without GSV graft(s) to revascularize the remaining target(s); and

- Group 4. In situ LITA graft to the LAD artery plus GSV graft(s) to revascularize all non-LAD targets.

Study groups are outlined in Figure 1. The RITA and the RA were managed as the second-choice conduit and were used to revascularize the secondary coronary target. The RA was always harvested from the nondominant arm. The RA was used either as a free graft in the aortocoronary configuration or in the $\mathrm{Y}$ configuration with the LITA; the latter was performed when the secondary target presented subocclusive stenosis. The RITA and RA grafts, irrespective to the configuration, were anastomosed to coronary targets with stenosis of $70 \%$ or greater. ${ }^{14,15}$ Because our experience with the use of the gastroepiploic artery as a bypass conduit is limited, the use of this conduit was excluded from the present study to avoid bias. $T$ grafts were never performed in the present series.

This trial was conducted under an intent-to-treat protocol. Reasons for incomplete fulfillment of the treatment assigned by randomization were as follows: intraoperative finding of coronary arteries unsuitable for grafting with the second-choice arterial conduit and intraoperative finding of first- or second-choice arterial graft unsuitable to perform a coronary graft. In consideration of the study inclusion criteria detailed above, 2 intraoperative conditions were defined to be determinants of exclusion from the study: (1) intraoperative conversion to off-pump CABG and (2) intraoperative finding of the LAD being unsuitable to receive grafts.

\section{Study End Points}

Study end points were in-hospital outcomes (mortality rate and morbidity), 2-year freedom from all-cause death, and adverse cardiac event-free survival (adverse cardiac events included cardiac death, acute myocardial infarction, recurrent angina, graft occlusion at coronary angiography, redo coronary surgery, or percutaneous transluminal coronary angioplasty).

\section{Surgical Procedure}

After a full median sternotomy and before opening the pericardium, the LITA and RITA (when applicable) were harvested in standard fashion before heparinization. Thoracic arteries were harvested skeletonized in all cases. When applicable, the RA was harvested before heparinization with a longitudinal forearm incision from the lateral edge of the biceps tendon up to a point between the radial styloid and the tendon of the flexor radialis muscle up to the wrist crease. Y grafts were constructed before establishment of CPB with end-to-side anastomosis of the RITA or RA segment to the LITA. After harvesting the conduits and after ascending aortic and right atrial cannulation, $\mathrm{CPB}$ was established, and the heart was arrested; myocardial protection was accomplished with antegrade and/or retrograde blood multidose cardioplegia according to the surgeon's preference. Arterial conduits were usually divided only after a clotting time of greater than 400 seconds to avoid intraluminal thrombosis. The conduits were then tested for 15 seconds to verify the adequacy of flow and were then carefully inspected to detect intraluminal thrombosis or luminal dissection. Manipulation was done gently as well. Immediately before performance of anastomosis, a papaverine solution was placed on arterial conduits to avoid vasospasm. For free grafts, the distal anastomosis usually preceded the proximal anastomosis. The latter was generally performed during aortic side clamping and with the heart beating. The distal anastomosis of free grafts usually preceded the distal anastomosis of in situ thoracic arteries. For sequential grafts, side-to-side anastomosis to the target coronary artery (diamond shaped) was performed. The order in which the anastomoses were performed remained under the discretion of the operating surgeon. The non-LAD, nonsecondary coronary targets, if present, received a GSV bypass graft in the aortocoronary configuration in all cases. After weaning from CPB, the adequacy of graft flow was assessed by using a Doppler probe after a systolic pressure of $80 \mathrm{~mm} \mathrm{Hg}$ was obtained. 

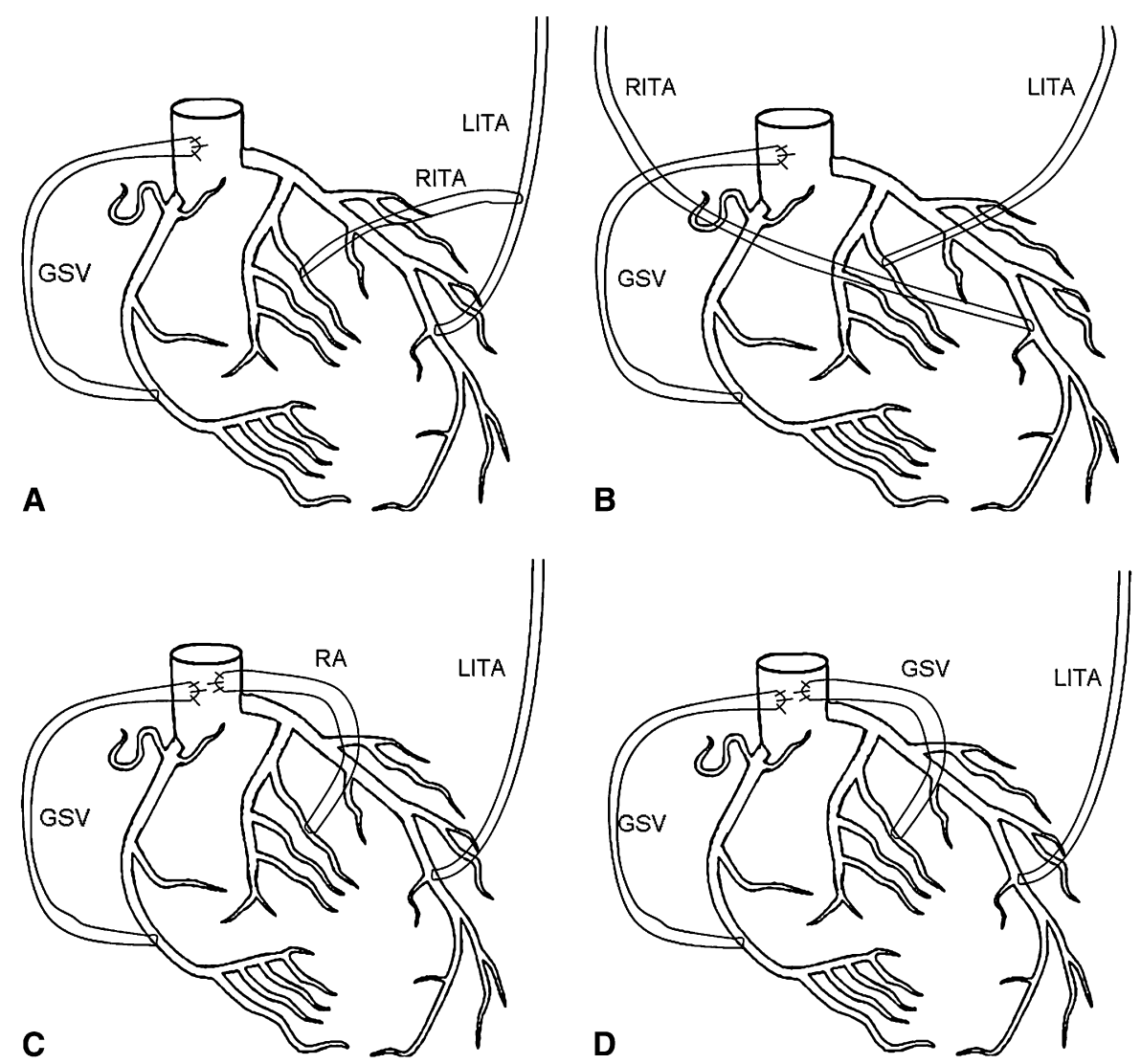

FIGURE 1. Schematic outline of the revascularization strategies in the study groups (the vessels of the lateral wall are depicted as the secondary coronary target). A, Group 1. Y graft: in situ left internal thoracic artery (LITA)-left anterior descending coronary artery and isolated right internal thoracic artery (RITA) to the secondary target with or without great saphenous vein $(G S V)$ graft(s). B, Group 2. In situ right internal thoracic artery (RITA)-left anterior descending coronary artery in situ left internal thoracic artery (LITA) to the secondary target with or without great saphenous vein (GSV) graft(s). C, Group 3. In situ left internal thoracic artery (LITA)-left anterior descending coronary artery and free radial artery $(R A)$ graft to the secondary target with or without great saphenous vein $(G S V)$ graft(s). Group 3 also includes a Y graft: in situ LITA-left anterior descending coronary artery and RA segment to the secondary target with or without GSV grafts. D, Group 4, Control group: in situ left internal thoracic artery (LITA)-left anterior descending coronary artery plus great saphenous vein (GSV) graft(s).

\section{Collection and Management of Data, Follow-up, and Statistical Analysis}

Preoperative, intraoperative, and postoperative data were obtained from the patients' charts during the hospitalization and were prospectively entered by the surgical assistants in an electronic database. A minimum dataset was established, including the details of coronary revascularization and postoperative mortality/morbidity relative to the study end points. Preoperative characteristics were defined according to the EuroSCORE criteria, as available online at www.euroscore.org. In particular, renal insufficiency was defined as a preoperative creatinine value of greater than $200 \mu \mathrm{mol} /$ L. Death was considered cardiac in origin when it was preceded by evident signs of cardiac disease/failure and its cause-effect link with the decease could be reasonably concluded.

Survivors were followed-up regularly 1 month after discharge, 6 months after discharge, and every year thereafter. Clinical examination and electrocardiographic and transthoracic echocardiographic analyses were done at every follow-up time point. In the case of recurrent ischemic symptoms, patients underwent myocardial perfusion nuclear scanning and coronary angiographic analysis if positive for ischemia. Mean follow-up time was $24.1 \pm 9.8$ months.

The final analysis of data was performed with SPSS software (version 11.0 for Windows; SPSS, Inc, Chicago, Ill). Discrete variables are ex- pressed as percentages, and continuous variables are expressed as means \pm standard deviation. Continuous data were compared by means of 1-way analysis of variance and subsequently by means of the multiplecomparison procedure (the Bonferroni correction) for multiple-group comparison. The Student $t$ test was used for 2-group comparison. For categorical data, between-groups comparison was done by using the nonparametric Kruskal-Wallis test or by using the $\chi^{2}$ test. Tests were 2-tailed when appropriate. The Yates correction was applied when appropriate. Time-to-event analysis was performed through Kaplan-Meier method, and corresponding survival curves were built; survival curves were compared by using the Wilcoxon test to detect differences in the early probabilities of survival. The $\alpha$ level was set at .05 .

\section{RESULTS}

From January 2003 to April 2006, a total of 1769 patients scheduled for coronary surgery were screened. Eight hundred fifteen individuals met the criteria for inclusion in the study; 1 patient refused surgical intervention, and 5 patients refused to enter the investigation. Thus 803 patients were finally enrolled in the study. A total of $46(4.8 \%)$ patients 
TABLE 1. Demographics and preoperative characteristics

\begin{tabular}{lcccc}
\hline \multicolumn{1}{c}{ Variable } & Group 1 & Group 2 & Group 3 & Group 4 \\
\hline Male sex & $56.2 \%$ & $56.7 \%$ & $56.9 \%$ & $58.4 \%$ \\
Age, mean (y) & $69.2 \pm 3.9$ & $68.4 \pm 4.6$ & $70.5 \pm 3.1$ & $69.7 \pm 3.5$ \\
Diabetes & $37.8 \%$ & $37.9 \%$ & $36.1 \%$ & $38.1 \%$ \\
Obesity & $13.9 \%$ & $13.1 \%$ & $14.3 \%$ & $13.9 \%$ \\
Recent AMI (<90 d) & $28.9 \%$ & $28.3 \%$ & $30.2 \%$ & $29.7 \%$ \\
NYHA III-IV & $68.7 \%$ & $68.2 \%$ & $69.3 \%$ & $68.8 \%$ \\
Chronic renal & $9.4 \%$ & $9.1 \%$ & $10.4 \%$ & $10.9 \%$ \\
$\quad$ insufficiency & & & & \\
COPD & $27.4 \%$ & $25.7 \%$ & $28.2 \%$ & $27.7 \%$ \\
EF <30\% & $14.4 \%$ & $12.6 \%$ & $14.8 \%$ & $13.9 \%$ \\
\hline AMI, Acute myocardial infarction; $N Y H A$, New York Heart Association; $C O P D$, \\
chronic obstructive pulmonary disease; $E F$, ejection fraction.
\end{tabular}

were excluded because of inadequate ulnar compensation during RA compression. Two hundred four patients were randomized to treatment group 1, 202 to group 2, 204 to group 3, and 205 to group 4. Twelve patients were excluded intraoperatively, and thus the final study population was composed by 201 patients in group 1, 198 in group 2, 202 in group 3, and 202 in group 4.

The preoperative characteristics of the study individuals in each group are compared in Table 1. Details of grafting performed in groups 1,2, and 3 are given in Table 2. A LITA-LAD (groups 1, 3, and 4) or RITA-LAD (group 2) graft was performed in all study individuals. The mean number of grafts per patient was $2.55 \pm 0.8$ in group $1,2.51 \pm$ 0.9 in group 2, $2.58 \pm 0.7$ in group 3, and $2.57 \pm 0.9$ in group $4(P=.41)$. The obtuse marginal branches of the circumflex artery were regarded most frequently as the secondary coronary target and received the second arterial conduit in the majority of cases. The right coronary artery and its branches and the diagonal or intermediate branches were less frequently considered the secondary target. A total of 318 GSV grafts (13 sequential) were implanted.

Table 3 displays the perioperative results. There were no statistically significant differences in terms of operative mortality rates (defined as death within 30 days after surgical intervention) among the 3 arterial revascularization groups $(P=.78)$. The difference in operative mortality between groups 1 to 3 versus group 4 was not significant $(P=.80$, Table 3). Length of intensive care unit stay, mechanical ven-
TABLE 2. Details of grafts in the arterial revascularization groups

\begin{tabular}{lccc}
\hline \multicolumn{1}{c}{ Variable } & Group 1 & Group 2 & Group 3 \\
\hline Second arterial conduit to OM branch & 105 & 109 & 119 \\
Second arterial conduit to I or D branch & 34 & 31 & 29 \\
Second arterial conduit to right & 51 & 54 & 48 \\
$\quad$ coronary system & & & \\
Sequential graft (second arterial conduit) & 11 & 4 & 7 \\
GSV graft & 110 & 102 & 116 \\
Complete revascularization (\% of patients) & $98.5 \%$ & $99.5 \%$ & $98.5 \%$ \\
\hline
\end{tabular}

Second arterial conduit: right internal thoracic artery in group 1 (Y graft), left internal thoracic artery in group 2 (in situ graft), and radial artery in group 3 (either aortocoronary or $\mathrm{Y}$ configuration with the left internal thoracic artery). $O M$, Obtuse marginal; $I$, intermediate branch; $D$, diagonal branch; $G S V$, great saphenous vein.

tilation time, and incidence of acute renal failure were comparable among the 4 groups. Cerebrovascular complications were more frequent in group 4 , although not statistically significant $(P=.0645$; odds ratio [OR], $0.63 ; 95 \%$ confidence interval $[C I], 0.38-1.03)$. Such a difference is likely a consequence of the more extensive manipulation of the ascending aorta required for the performance of a higher number of proximal anastomoses on the ascending aorta in group 4 . Higher mean CPB time was also observed in group $4(P=$ .033). No patient who had the RA harvested complained of ischemic symptoms of the hand in either the early postoperative period or the follow-up period. There were 6 cases of mediastinitis (3 in group 1, 2 in group 2, and 1 in group 4).

Three patients were lost at follow-up. The overall mortality rate in the global study population was $3.6 \%$. The end of follow-up mortality rate was $3.5 \%$ in group $1,2.5 \%$ in group $2,3.5 \%$ in group 3 , and $4.9 \%$ in group $4(3.2 \%$ in groups $1-3$ and $4.9 \%$ in group 4 ). Both multiple-group comparison and 2-group comparison (groups 1-3 vs group 4) reported that this difference was not statistically significant $(P=.62$ and $P=.33$, respectively; OR, $0.63 ; 95 \%$ CI, 0.27-1.47). Death was cardiac in origin in 24 cases (12 acute myocardial infarctions, 7 arrhythmic sudden deaths, and 5 cases of progressive heart failure). Cardiac death at follow-up occurred more frequently in group 4 versus groups 1 to $3(4.4 \%$ vs. $2.5 \%)$, but this difference failed to reach a significant probability value $(P=.23$; OR, 0.55 ; $95 \%$ CI, 0.22-1.38). Adverse cardiac events were significantly less frequent in groups 1 to 3 versus group $4(P<.0001)$.

TABLE 3. Perioperative results

\begin{tabular}{lccccc}
\hline \multicolumn{1}{c}{ Variable } & Group 1 & Group 2 & Group 3 & Group 4 & P value \\
\hline Operative mortality rate & $2.5 \%$ & $2.0 \%$ & $2.5 \%$ & $3.0 \%$ & .78 \\
CPB time (min) & $66.4 \pm 10.5$ & $68.9 \pm 9.5$ & $67.9 \pm 10.4$ & $81.5 \pm 12.4$ \\
Crossclamp time (min) & $34.5 \pm 10.3$ & $33.7 \pm 9.1$ & $35.6 \pm 9.8$ & $36.5 \pm 11.2$ \\
ICU stay (h) & $38.8 \pm 10$ & $39.2 \pm 8.9$ & $38.9 \pm 9.1$ & $40.7 \pm 11.4$ \\
Ventilation time (h) & $29.9 \pm 6$ & $30.4 \pm 5.1$ & $30.2 \pm 5.2$ & $31.5 \pm 6.1$ & NS \\
Stroke/TIA & $2.5 \%$ & $2.0 \%$ & $3.0 \%$ & $4.9 \%$ & NS \\
Acute renal failure & $6.5 \%$ & $5.6 \%$ & $6.9 \%$ & .0645 \\
\hline
\end{tabular}

$C P B$, Cardiopulmonary bypass; $I C U$, intensive care unit; TIA, transient ischemic attack. 
TABLE 4. Follow-up results: mortality rate and cases of adverse cardiac events (arterial revascularization [groups 1-3] versus traditional revascularization [group 4])

\begin{tabular}{lccc}
\hline \multicolumn{1}{c}{ Variable } & $\begin{array}{c}\text { Arterial } \\
\text { revascularization } \\
\text { (groups 1-3) }\end{array}$ & $\begin{array}{c}\text { Traditional } \\
\text { revascularization } \\
\text { (group 4) }\end{array}$ & $\boldsymbol{P}$ value \\
\hline $\begin{array}{l}\text { End of follow-up } \\
\quad \text { mortality rate }\end{array}$ & $3.2 \%$ & $4.9 \%$ & .33 \\
$\quad$ all causes) & & & \\
Cardiac death & $15(2.5 \%)$ & $9(4.4 \%)$ & .239 \\
Recurrent angina & 18 & 22 & $<.001$ \\
AMI & 8 & 8 & .0018 \\
PTCA & 9 & 12 & .001 \\
Graft occlusion & 21 & 26 & $<.001$ \\
Redo coronary surgery & 1 & 2 & .048 \\
\hline AMI, Acute myocardial infarction; $P T C A$, percutaneous transluminal coronary angio- \\
plasty.
\end{tabular}

Details are reported in Table 4. In any case, the multiplegroup comparison excluded statistically significant differences in the rate of adverse cardiac events between groups 1,2 , and $3(P=.25)$. Control coronary angiographic analysis was performed in a total of 59 patients.

Kaplan-Meier analysis showed no statistically significant overall survival advantage in any study group (Figure 2). In any case, when the adverse cardiac event-free survival is considered, groups 1,2 , and 3 had a significant advantage over group 4 (Wilcoxon test: overall, $P<.0001$ with 3 degrees of freedom; pairwise comparison of group 1 vs group $4, P=.0004$; group 2 vs group $4, P=.0001$; group 3 vs group $4, P=.0046$; Figure 3$)$. Conversely, cardiac eventfree survival was similar among groups 1,2 , and 3 (Wilcoxon test: pairwise comparison of group 1 vs group 2, $P=.744$; group 1 vs group $3, P=.387$; group 2 vs group

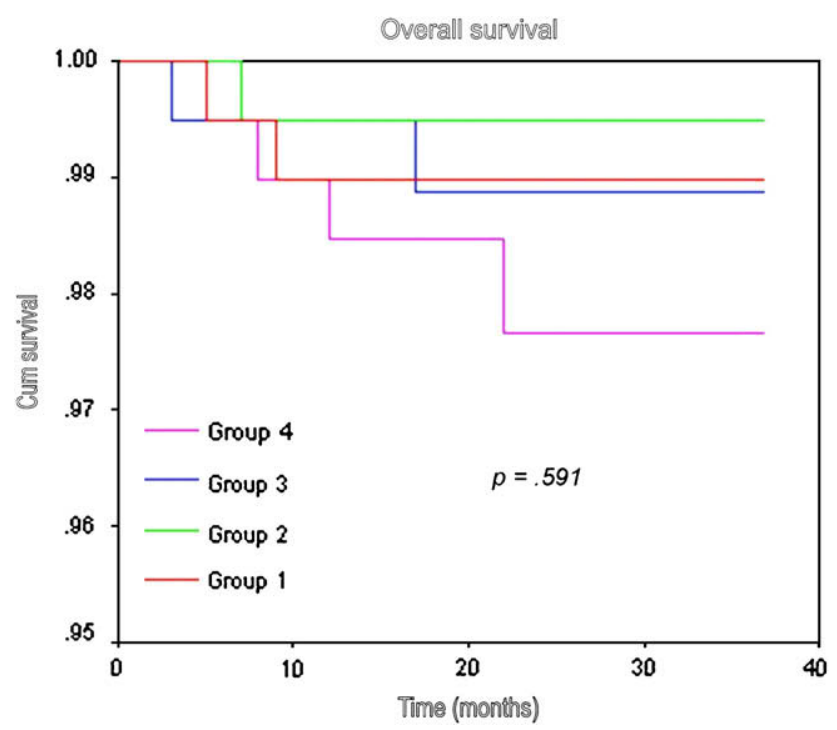

FIGURE 2. Overall survival at the end of the follow-up period in the 4 study groups.

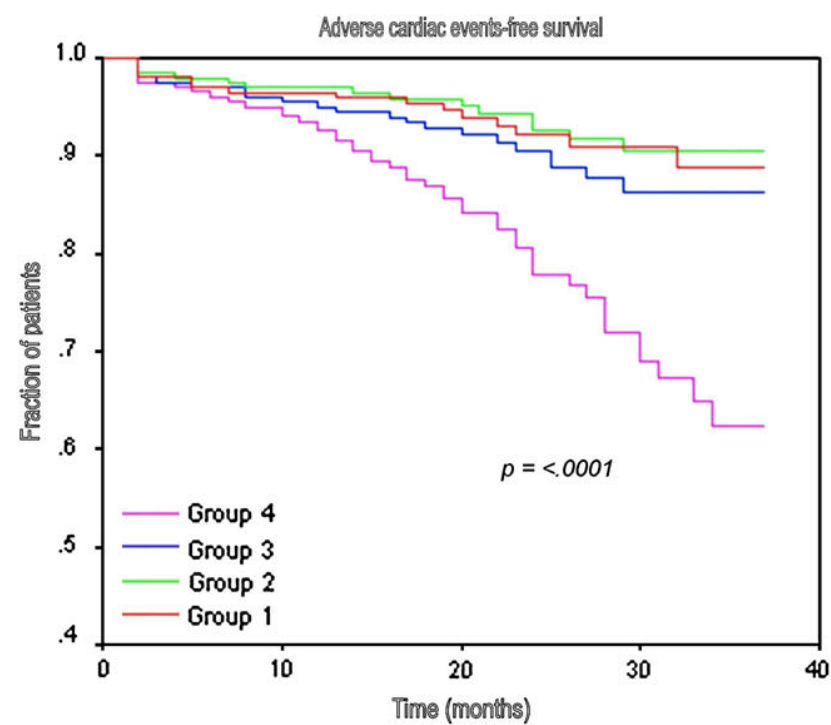

FIGURE 3. Freedom from adverse cardiac events at the end of the followup period in the 4 study groups.

3, $P=.233$ ). Additional Kaplan-Meier curves were built to investigate the effects of the strategy of revascularization in younger versus elderly patients, dividing the population into 4 strata: either younger than 75 years or older than 75 years and receiving 1 arterial conduit (LITA-LAD, group 4 ) and either younger than 75 years or older than 75 years and receiving 2 arterial conduits (groups 1-3, Figure 4). The elderly patients had a statistically significant disadvantage in terms of event-free survival if they had received

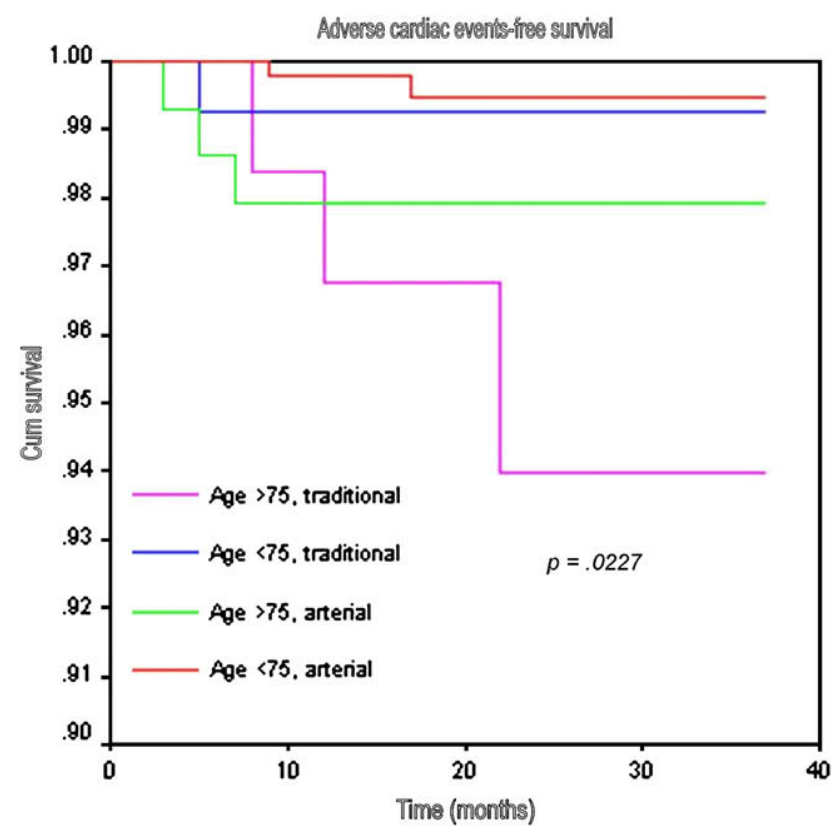

FIGURE 4. Freedom from adverse cardiac events in patients younger and older than 75 years (arterial revascularization vs traditional revascularization). 
only 1 arterial conduit rather than 2 arterial grafts (Wilcoxon test: overall, $P=.0227$ with 3 degrees of freedom; pairwise comparison of patients younger than 75 years receiving arterial revascularization vs patients older than 75 years receiving traditional revascularization, $P=.0015)$. Results indicate that each of the revascularization strategies using 2 arterial conduits analyzed herein has optimal results in terms of event-free survival at the 2-year follow-up at a comparable level in the younger and elderly patients (the pairwise comparisons yielding not statistically significant $P$ values).

\section{DISCUSSION}

The superiority of the LITA over GSV grafts in revascularization of the LAD has been clearly demonstrated ${ }^{1,2}$ and was among the determinants of the improved results of CABG surgery in the treatment of multivessel coronary disease. On this basis, total arterial revascularization has been forwarded as an additional and powerful tool to ameliorate the results of coronary surgery. However, its potential role has been questioned by the finding that the outcomes of the GSV grafts might be better than expected ${ }^{9}$ and by the increasing age of the population submitted to CABG. The latter factor has induced some groups to avoid extra-arterial conduits other than the LITA in the attempt to reduce the surgical trauma mainly in elderly patients, who have shorter life expectancies and hence less likelihood to benefit from the durability of the arterial conduits. Conversely, other randomized trials have indicated that total arterial revascularization significantly ameliorates the patients' outcome, even in the contemporary patient populations, including elderly surgical candidates. ${ }^{8}$ In this complex scenario it is unclear (1) whether the use of 2 arterial conduits significantly ameliorates the patients' outcome, even though GSV grafts are used to revascularize the remaining targets, and (2) whether different strategies of revascularization with 2 arterial conduits under different configurations are equivalent with respect to midterm results. The present study was started with the aim to contribute to these issues and was designed as a prospective randomized investigation to perform a direct comparison of 4 different surgical strategies without selection bias.

The main findings can be summarized as follows. The 3 strategies of revascularization with 2 arterial conduits, as presented herein, yielded comparable results at 2-year follow-up. None of them appeared to confer significant advantages in terms of overall survival and adverse cardiac event-free survival over the remaining 2 strategies. This reasonably implies that the results associated with the use of the RITA, either as a Y graft or as a pedicled graft to the LAD, are not significantly different to those obtained with the RA, either as a Y graft or as a free aortocoronary graft. As an additional implication, surgeons might indifferently use either the RA or the RITA as the secondary arterial conduit on the basis of the characteristics of the individual patients (ie, coexistence of risk factors for mediastinitis or impossibility to harvest the RA safely), with reasonable expectations of good results in either case. Our data are in line with previous findings, indicating the reliability and the excellent performances of the RITA when used to revascularize the left coronary system. ${ }^{16,17}$ Our data also strengthen the concept of the equivalence of the clinical results associated with the RA and the RITA used to revascularize the secondary coronary target. ${ }^{18}$ In any case, in the previous studies no insights were made available over the results of different configurations of grafts, and no conclusive data were provided. Essentially our data support the equivalence in clinical and angiographic results of different configurations of LITA and RITA grafts (either in situ or as a Y or T graft), which has been previously underscored. ${ }^{19,20}$ Similar findings were also obtained a propos of the RA used either as a free aortocoronary graft or as a Y graft with the LITA. ${ }^{21}$ Previous studies have suggested that the midterm outcomes might not be different in the current era if a GSV graft or a free RA graft is used to revascularize the secondary target. $^{22}$ In any case, in our analysis we have regarded as adverse cardiac events not only myocardial infarction, percutaneous intervention, and redo coronary surgery but also recurrent angina. This has a major effect on patients; the possibility to reduce its incidence by using a second arterial conduit rather than a GSV should be strongly addressed.

Despite overall survival at the 2-year follow-up being comparable among the 4 study groups, the cardiac adverse event-free survival was significantly better in groups 1 to 3 versus that seen in the patients who had only 1 arterial graft. Such a finding can be reasonably ascribed to the lower incidence of graft failure within groups 1 to 3 . A reduced incidence of follow-up myocardial infarction and percutaneous transluminal coronary angioplasty/coronary reintervention has been already observed after bilateral ITA grafting., ${ }^{5,6}$ The present study indicates that similar results can be obtained, irrespective of which second arterial conduit among the RITA and RA is used and irrespective of graft configuration. Therefore provided that the second-choice arterial conduit is used to revascularize the secondary coronary target, the use of at least 1 additional arterial graft offers better results, even though GSV grafts are used to revascularize the remaining targets. This implies that the use of 2 arterial grafts, even though the revascularization is not entirely accomplished with arterial conduits, might be justified from the point of view of the surgical risk/benefit balance. The benefits of coronary revascularization with 2 arterial conduits might be evident not only at the midterm follow-up under the features of event-free survival but also in the early postoperative period in terms of less incidence of perioperative cerebrovascular complications. Our study cannot provide a definite answer on this problem because the sample size is probably 
insufficient and the real clinical difference among groups, if present, might be little. In any case, we believe that further insights are warranted because the prevalence of moderateto-severe ascending aortic atherosclerosis is likely to increase with the aging of the $\mathrm{CABG}$ population.

At 2 years after the operation, the improvement in adverse cardiac event-free survival associated with the use of 2 arterial conduits (groups 1-3) versus that seen in patients who had only 1 arterial graft (group 4) was also evident in the elderly patients ( $>75$ years). The difference was statistically significant (Figure 4). Therefore the use of an additional arterial conduit in the elderly, mainly in the presence of good life expectancy, might be justified despite increased surgical trauma and technical challenges. ${ }^{23} \mathrm{We}$ acknowledge that the present investigation is not focused on the elderly surgical candidates and that they correspond to a minor proportion of our sample; these represent the main limitation to our conclusions over this subgroup.

Previous studies have suggested that if both ITAs are used to revascularize the left coronary system, the results at the midterm are not affected by the type of graft used for the right coronary target, either the GSV or another arterial graft. ${ }^{24}$ It has been also suggested that the most important coronary target for the RITA (as the second-choice arterial conduit) is the lateral wall rather than the right coronary system. ${ }^{25}$ In our investigation the branches of the circumflex artery were most frequently the secondary coronary target and thus received most frequently the second-choice arterial conduit. The right coronary system was regarded as the secondary target only in a minority of cases. In this scenario our data raise a major question: whether true total arterial revascularization can be reasonably expected to yield significantly better results than revascularization with 2 arterial conduits (used to revascularize the primary and the secondary coronary targets) plus GSV grafts to the remaining targets, as described in the present investigation. Probably total arterial revascularization will not provide a significant advantage and will be unjustified in many cases, mainly if revascularization is needed in the territory of the right coronary system. A prospective direct comparison, including stratification on the basis of patients' age, is therefore needed. The results of the cohort of patients presented herein at longer follow-up intervals will provide additional useful information.

As the main study limitations, we acknowledge the relatively short-term follow-up and the lack of routine angiographic confirmation of graft patency. Longer follow-up periods will provide important data about the durability of the benefits associated with the use of 2 arterial grafts, even in elderly patients, and will allow a more reliable comparison among alternative procedures.

In conclusion, myocardial revascularization with 2 arterial conduits in multivessel coronary disease offers better event-free survival compared with a single arterial graft
(LITA-LAD strategy), irrespective of which conduit is used as the second-choice arterial grafts (RITA or RA) and irrespective of the configuration used ( $\mathrm{Y}$ graft or in situ RITA graft or aortocoronary RA graft). Such benefits are evident, even in elderly patients. The advantage in terms of the perioperative cerebrovascular event rate associated with the use of 2 arterial conduits rather than a single conduit might be little or absent. Finally, this study prompts ongoing research on the comparison between total arterial revascularization and revascularization strategies with 2 arterial conduits with or without GSV grafts.

\section{References}

1. Loop FD, Lytle BW, Cosgrove DM, Stewart RW, Goormastic M, Williams GW, et al. Influence of the internal-mammary-artery graft on 10-year survival and other cardiac events. N Engl J Med. 1986;314:1-6.

2. Cameron A, Davis KB, Green G, Schaff HV. Coronary bypass surgery with internal thoracic artery grafts-effects on survival over a 15-years period. $N$ Engl J Med. 1996;334:261-9.

3. Pick AW, Orszulak TA, Anderson BJ, Schaff HV. Single versus bilateral internal thoracic artery grafts: 10-years outcome analysis. Ann Thorac Surg. 1997;64: 599-605.

4. Stevens LM, Carrier M, Perrault LP, Hébert Y, Cartier R, Bouchard D, et al. Influence of diabetes and bilateral internal thoracic artery grafts on long-term outcome for multivessel coronary artery bypass grafting. Eur J Cardiothorac Surg. 2005;27:281-8.

5. Lytle BW, Blackstone EH, Loop FD, Houghtaling PL, Arnold JH, Akhrass R, et al. Two internal thoracic artery grafts are better than one. J Thorac Cardiovasc Surg. 1999;117:855-72.

6. Calafiore AM, Di Mauro M, Di Giammarco G, Teodori G, Iacò L, Mazzei V, et al. Single versus bilateral internal mammary artery for isolated first myocardial revascularization in multivessel disease: long-term clinical results in medically treated diabetic patients. Ann Thorac Surg. 2005;80:888-95.

7. Muneretto C, Negri A, Manfredi J, Terrini A, Rodella G, Elgarra S, et al. Safety and usefulness of composite grafts for total arterial myocardial revascularization: a prospective randomized evaluation. J Thorac Cardiovasc Surg. 2003 125:826-35

8. Muneretto C, Bisleri G, Negri A, Manfredi J, Metra M, Nodali S, et al. Total arterial myocardial revascularization with composite grafts improves results of coronary surgery in the elderly; a prospective randomized comparison with conventional coronary artery bypass surgery. Circulation. 2003;108(suppl I):II29-33.

9. Hayward PA, Buxton BF. Contemporary coronary graft patency: 5-year observational data from a randomized trial of conduits. Ann Thorac Surg. 2007;84:795-9.

10. Glineur D, Noirhomme P, Reisch J, El Khoury G, Astarci P, Hanet C. Resistance to flow of arterial Y-grafts 6 months after coronary artery bypass surgery. Circulation. 2005;112(suppl):I281-5.

11. The American College of Cardiology/American Heart Association Task Force for Practice Guidelines. ACC/AHA 2004 guideline update for coronary artery bypass graft surgery. Circulation. 2004;110:340-437.

12. Pola P, Serricchio M, Flore R, Manasse E, Favuzzi A, Possati GF. Safe remova of the radial artery for myocardial revascularization: a Doppler study to prevent ischemic complications of the hand. J Thorac Cardiovasc Surg. 1996;112: 737-44.

13. The Parisian Mediastinitis Study Group. Risk factors for deep sternal wound infection after sternotomy: a prospective, multicenter study. J Thorac Cardiovasc Surg. 1996;111:1200-7.

14. Possati G, Gaudino M, Prati F, Alessandrini F, Trani C, Glieca F, et al. Long-term results of the radial artery used for myocardial revascularization. Circulation. 2003;108:1350-4.

15. Gaudino M, Alessandrini F, Pragliola C, Cellini C, Glieca F, Luciani N, et al Effect of target artery location and severity of stenosis of mid-term aortaanastomosed vs. internal thoracic artery-anastomosed radial artery grafts. Eur J Cardiothorac Surg. 2004;25:424-8.

16. Pevni D, Mohr R, Uretzky G, Lev-Ran O, Paz J, Kramer A, et al. Free right internal thoracic artery composite graft: an option in left anterior descending artery grafting? Ann Thorac Surg. 2002;74:2208-9.

17. Buxton BF, Ruengsakulrach P, Fuller J, Rosalion A, Reid CM, Tatoulis J. The right internal thoracic artery graft-benefits of grafting the left coronary system 
and native vessels with a high grade stenosis. Eur J Cardiothorac Surg. 2000;18: 255-61.

18. Hayward P, Hare DL, Gordon I, Matalanis G, Buxton BF. Which arterial conduit? Radial artery versus free right internal thoracic artery: six-year clinical results of a randomized controlled trial. Ann Thorac Surg. 2007;84:493-7.

19. Calafiore AM, Contini M, Vitolla G, Di Mauro M, Mazzei V, Teodori D, et al. Bilateral internal thoracic artery grafting: long-term clinical and angiographic results of in situ versus Y grafts. J Thorac Cardiovasc Surg. 2000;120:990-6.

20. Lev-Ran O, Mohr M, Uretzky G, Pevni D, Locker C, Paz Y, et al. Graft of choice to right coronary system in left-sided bilateral internal thoracic artery grafting. Ann Thorac Surg. 2003;75:88-92.

21. Lemma M, Mangini A, Gelpi G, Innorta A, Spina A, Antona C. It is better to use the radial artery as a composite graft? Clinical and angiographic results of aortocoronary versus Y graft. Eur J Cardiothorac Surg. 2004;26:110-7.
22. Hayward P, Hare DL, Gordon I, Buxton BF. Effect of radial artery or saphenous vein conduit for the second graft on 6-year clinical outcome after coronary artery bypass grafting. Results of a randomized trial. Eur J Cardiothorac Surg. 2008;34: 113-7.

23. Muneretto C, Bisleri G, Negri A, Manfredi J, Carone E, Morgan JA, et al. Left internal thoracic artery-radial artery composite graft as the technique of choice for myocardial revascularization in elderly patients: a prospective randomized evaluation. J Thorac Cardiovasc Surg. 2004;127:179-84.

24. Pevni D, Uretzky G, Yosef P, Yanay BG, Shapira I, Nesher N, et al. Revascularization of the right coronary artery in bilateral internal thoracic artery grafting. Ann Thorac Surg. 2005;79:564-9.

25. Schmidt SE, Jones JW, Thornby JI, Miller CC 3rd, Beall AC Jr. Improved survival with multiple left-sided bilateral internal thoracic artery grafts. Ann Thorac Surg. 1997;64:9-14. 